\title{
FORMULATION DEVELOPMENT AND EVALUATION OF ALLOPURINOL SOLID DISPERSIONS BY SOLVENT EVAPORATION TECHNIQUE
}

\section{RAMSHETTI RAJENDRA PRASADa, JADI RAJENDRA KUMAR, ${ }^{\mathrm{b}, \mathrm{c}}$, BAKSHI VASUDHA ${ }^{\mathrm{b}}$, CHETTUPALLI ANANDA KUMAR $^{\mathbf{b}}$}

aChaitanya College of Pharmacy Education and Research, Kishanpura, Hanamkonda, Warangal 506001, TS, India, bAnurag Group of Institutions, School of Pharmacy, (Formerly Lalitha College of Pharmacy), Venkatapur, Ghatkesar, Medchal, Hyderabad 500088, TS, India, cUniversity College of Technology, Osmania University, Hyderabad 500007, TS, India Email: anand33.chettuplli@gmail.com

Received: 15 Feb 2018, Revised and Accepted: 16 Jun 2018

\section{ABSTRACT}

Objective: The main objective of the research work is to develop and characterize allopurinol (ALPN) solid dispersions with different polymers to enhance solubility, enrich dissolution profile and improve patient compliance.

Methods: ALPN solid dispersions were prepared by solvent evaporation technique using various grades of polyethelene glycol (PEG) such as PEG 4000 and PEG 6000 with different ratios like 1:0.5, 1:1, 1:1.5 and 1:2 and after formation of solid dispersions all physicochemical properties were examined.

Results: All the formulations were found within the permissible pharmacopoeial limits for various physicochemical parameters. The preformulation studies, like Fourier, transform infrared spectroscopy (FTIR) showed the absence of drug-excipient interactions. The solubility and dissolution profiles of the sample were increased with increasing the concentration of ALPN solid dispersions. Solvent evaporation was proved to be a successful technique for the development of stable solid dispersion of ALPN. The dissolution amount percentage of ALPN formulations was found between $39.58 \pm 2.5$ to $94.95 \pm 1.8 \%$ within $60 \mathrm{~min}$.

Conclusion: Hence, from the all evaluation studies, it was evident that F1 formulation was the better formulation. F1 formulation (ALPN: PEG 4000 in the ratio of 1:0.5), $94.95 \pm 1.8 \%$ drug released within $50 \mathrm{~min}$.

Keywords: Solid dispersions, Polyplasdone XL, Compressibility, Flowability

(C) 2018 The Authors. Published by Innovare Academic Sciences Pvt Ltd. This is an open access article under the CC BY license (http://creativecommons.org/licenses/by/4.0/) DOI: http://dx.doi.org/10.22159/ijap.2018v10i4.25311

\section{INTRODUCTION}

From the several previous years, the pharmaceutical scientists were working to increase patient compliance and secure dosage forms due to the improved requirement in the market for them. As a result, developing the novel technologies has been growing annually because the growth of novel drug molecules requires higher cost rather than novel technology. So the current trend in the greater part of pharmaceutical industries is a development of dosage form with new formulation technology using old drug molecules to improve safety, efficacy and patient compliance [1, 2]. It is active for the treatment of both major hyperuricemias of gout and minor hyperuricemia related to haematological complaints or antineoplastic therapy [3]. It is a very weak acid with a dissociation constant (pKa) of 9.4 and is consequently principally unionized at all functional $\mathrm{pH}$ values [4]. The aforementioned lipid solubility is relatively low as is specified by its octanol: water partition coefficient of 0.28 [5]. ALPN is a polar composite thru tough intermolecular hydrogen relationship and narrow solubility in both polar and non-polar media [6]. Solid dispersion procedures used far and wide, to progress the dissolution possessions and bioavailability of poorly water-soluble drugs [7]. Solid dispersion means for a set of solid products comprising of at least two different components, usually a hydrophobic drug and a hydrophilic matrix. The matrix can be any crystalline or amorphous and drugs can be dispersed molecularly. The molecular dispersion can depend on the degree of supersaturation and rate of cooling in the process. The important limitation of this method is the thermal stability of the drug and the carrier. If temperature requires too high, the drug may decompose or evaporate. It is furthermore definite as being an origination made by fluctuating a fluid drug-carrier amalgamation to the compacted state [8]. The intention of the current revision was to prepare ALPN solid dispersions by a solvent evaporation method and the process for the enhancement of solubility of the drug.

\section{MATERIALS AND METHODS}

\section{Materials}

ALPN was kindly provided by Sura labs, Hyderabad, Telangana, India. PEG 4000, PEG 6000, polyplasdone XL and microcrystalline cellulose were purchased from Nihal trader's Pvt. Ltd., Hyderabad, Telangana. Aerosol and magnesium stearate were procured from SD Fine-Chemicals limited, Mumbai. Hydrochloric acid $(\mathrm{HCl})$ was supplied from Merck Specialities Pvt. Ltd., Mumbai.

\section{Methods}

Drug-excipient compatibility studies

Drug-excipient interaction studies carried out by using FTIR, mixing the drug and excipients in various proportions.

\section{Pre-compression studies}

The powder mixtures of all ALPN formulations were evaluated for angle of repose, bulk density, tapped density, compressibility index and Hausner's ratio [9].

Preparation of solid dispersions by solvent evaporation method

Methanol was used as a solvent. ALPN dose was taken as $100 \mathrm{mg}$. Watersoluble polymers such as PEG 4000 and PEG 6000 were selected as carriers. Drug and polymers were taken in different ratios such as 1:0.5, $1: 1,1: 1.5,1: 2$ stated in the formulation chart (table 1). The prepared solid dispersions were passed through the \# 20 sieve number to get uniform sized particles [10-16]. Add required quantities of diluent, lubricant and glidant to the above mixer. The prepared complex samples were stored at ambient conditions for further studies [17-18].

\section{Preparation of tablets by the direct compression method}

The tablets were prepared by 8 station compression machine using $10 \mathrm{~mm}$ flat surfaced punch. The hardness of the tablets was maintained at $4.0-5.0 \mathrm{~kg} / \mathrm{cm}^{2}[19]$. 


\section{Post-compression studies}

The prepared formulations were categorized with their uniformity of weight, thickness, hardness, friability, disintegration time and drug content uniformity [20].

\section{In vitro drug release studies}

The drug release rate was deliberate using the USP type II dissolution test device. The dissolution medium was $900 \mathrm{ml}$ of $0.1 \mathrm{~N} \mathrm{HCl}(\mathrm{pH} 1.2)$ at $50 \mathrm{rpm}$ at a temperature of $37 \pm 0.5^{\circ} \mathrm{C}$. Samples of $5 \mathrm{ml}$ were calm at from time to time up to $60 \mathrm{~min}$. and analyzed later proper dilution by using UV visible spectrophotometer at 250 nm [21].

\section{RESULTS AND DISCUSSION}

\section{Drug-excipient compatibility studies}

The drug excipient compatibility study was supported by using Fourier transmission infrared spectroscopy (FTIR) and it is shown in fig. 1 and fig. 2 . They were showing the principal peaks at similar wavenumbers. And in the optimized formulation (F1) some different wave numbers observed. However, these additional peaks were observed with physical mixtures, which could be due to the presence of polymers. These results suggest that there is no interaction between the drug and polymers used in the present study. Hence the excipients are used in this study are inert with drug and are suitable for the formulation development.

Table 1: Formulation table showing various compositions

\begin{tabular}{|c|c|c|c|c|c|c|c|c|c|}
\hline Ingredients (mg/tab) & F1 & F2 & F3 & F4 & F5 & F6 & F7 & F8 & F9 \\
\hline Drug & 100 & 100 & 100 & 100 & 100 & 100 & 100 & 100 & 100 \\
\hline PEG 4000 & 50 & 100 & 150 & 200 & - & - & - & - & 100 \\
\hline PEG 6000 & - & - & - & - & 50 & 100 & 150 & 200 & 100 \\
\hline Polyplasdone XL & 30 & 30 & 30 & 30 & 30 & 30 & 30 & 30 & 30 \\
\hline Aerosil & 5 & 5 & 5 & 5 & 5 & 5 & 5 & 5 & 5 \\
\hline Mg. stearate & 5 & 5 & 5 & 5 & 5 & 5 & 5 & 5 & 5 \\
\hline MCC & q. $s$ & q. s & q. $s$ & q. $s$ & q. s & q. $s$ & q. $s$ & q. s & q. $s$ \\
\hline
\end{tabular}

Total weight of tablets $=500 \mathrm{mg}$

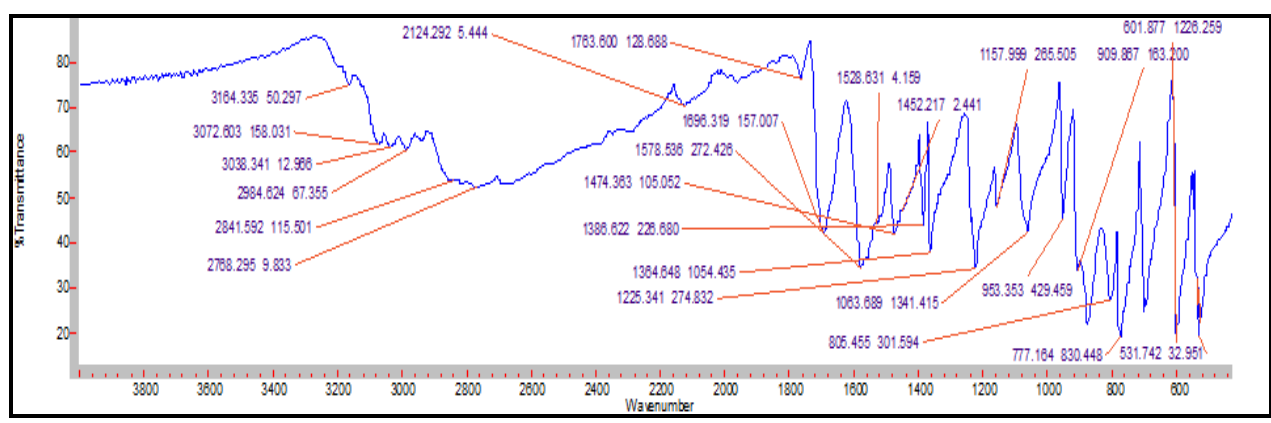

Fig. 1: FTIR spectra of pure drug (ALPN)

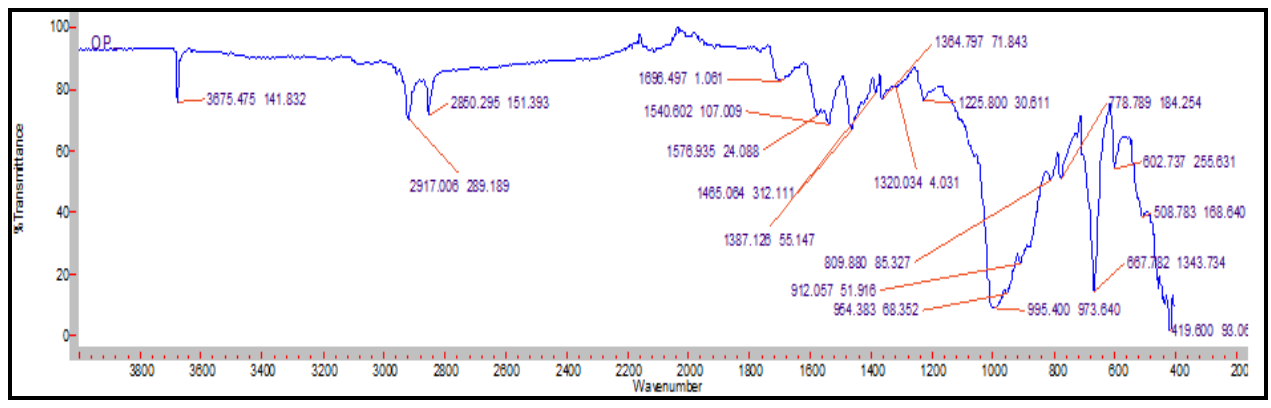

Fig. 2: FTIR spectra of optimized formulation (F1)

Table 2: Physical properties of the pre-compression blend

\begin{tabular}{|c|c|c|c|c|c|}
\hline Formulation code & $\begin{array}{l}\text { Angle of } \\
\text { repose* }^{*}(\theta)\end{array}$ & $\begin{array}{l}\text { Bulk density* } \\
\left(\mathrm{gm} / \mathrm{cm}^{3}\right)\end{array}$ & $\begin{array}{l}\text { Tapped density* } \\
\left(\mathrm{gm} / \mathrm{cm}^{3}\right)\end{array}$ & Carr's index* (\%) & Hausner's ratio* \\
\hline F1 & $28.61 \pm 1.202$ & $0.61 \pm 0.424$ & $0.61 \pm 0.963$ & $10.135 \pm 1.12$ & $1.03 \pm 0.024$ \\
\hline $\mathrm{F} 2$ & $27.48 \pm 0.981$ & $0.48 \pm 0.378$ & $0.63 \pm 0.896$ & $10.623 \pm 0.18$ & $0.99 \pm 0.015$ \\
\hline F3 & $24.01 \pm 0.674$ & $0.69 \pm 0.912$ & $0.58 \pm 0.003$ & $8.977 \pm 2.48$ & $1.13 \pm 0.028$ \\
\hline F4 & $24.36 \pm 0.267$ & $0.63 \pm 1.065$ & $0.61 \pm 0.458$ & $9.183 \pm 1.06$ & $1.18 \pm 0.019$ \\
\hline F5 & $26.01 \pm 0.938$ & $0.66 \pm 1.125$ & $0.63 \pm 0.955$ & $10.967 \pm 0.39$ & $1.17 \pm 0.056$ \\
\hline F6 & $23.80 \pm 0.816$ & $0.62 \pm 0.089$ & $0.64 \pm 0.123$ & $9.825 \pm 0.82$ & $1.21 \pm 0.029$ \\
\hline F7 & $24.09 \pm 1.045$ & $0.49 \pm 0.016$ & $0.69 \pm 0.896$ & $8.150 \pm 0.91$ & $1.13 \pm 0.614$ \\
\hline F8 & $29.18 \pm 0.183$ & $0.66 \pm 0.925$ & $0.58 \pm 0.912$ & $9.638 \pm 1.67$ & $1.22 \pm 0.926$ \\
\hline F9 & $24.47 \pm 1.027$ & $0.60 \pm 0.141$ & $0.61 \pm 0.018$ & $10.901 \pm 1.96$ & $1.19 \pm 0.034$ \\
\hline
\end{tabular}

Each value represents mean \pm SD $(n=3)$. 


\section{Pre-compression studies}

The angle of repose of ALPN was determined by funnel method and it was found in the ranges of $24.01 \pm 0.674$ to $29.18 \pm 0.183$. Bulk density and tapped density was found between $0.66 \pm 1.125$ to $0.60 \pm 0.141$ and $0.61 \pm 0.963$ to $0.69 \pm 0.896$ respectively. Carr's index and hausner's ratios were found to be $<11$ and $<1.25$ respectively. Pre-compression blends studies representing fair to good flow properties and it was shown in table 2 .

\section{Preparation of standard graph}

ALPN standard graph was achieved by various concentrations (10 to $59 \mu \mathrm{g} / \mathrm{ml}$ ) of drug and correlation coefficient $\left(\mathrm{R}^{2}\right)$ was attained at 0.999 . The $\mathrm{R}^{2}$ shows that limit of detection (LOD), limit of quantification (LOQ), dynamic range, and limit of linearity (LOL).

\section{Post-compression studies}

The weight variation was found in the ranges from $497 \pm 4.24$ to $504 \pm 0.23 \mathrm{mg}$. The hardness $(\mathrm{n}=6)$ of the tablets ranged from $3.9 \pm 0.81$ to $4.8 \pm 1.06 \mathrm{~kg} / \mathrm{cm}^{2}$ and the friability $(\mathrm{n}=10)$ ranged from $0.298 \pm 0.497 \%$. The thickness $(\mathrm{n}=20)$ of the tablets stretched from $4.92 \pm 0.05$ to $4.99 \pm 0.02 \mathrm{~mm}$ and the content of the drug $(\mathrm{n}=6)$ is $98.84 \pm 0.76$ to $100.35 \pm 0.50 \%$. Consequently, all the physical aspects of all formulations were imitated to in the official limits and it was shown in table 3.

Table 3: Physical evaluation of ALPN prepared tablets

\begin{tabular}{|c|c|c|c|c|c|}
\hline Formulation code & Weight variation ${ }^{\mathrm{a}}$ (mg) & Thickness $^{\mathrm{b}}(\mathrm{mm})$ & $\begin{array}{l}\text { Hardness }^{\mathrm{c}} \\
\left(\mathrm{Kg} / \mathrm{cm}^{2}\right)\end{array}$ & Friability ${ }^{\mathrm{b}}(\%)$ & Content uniformity $(\%)$ \\
\hline F1 & $500 \pm 2.02$ & $4.99 \pm 0.84$ & $4.5 \pm 0.52$ & $0.492 \pm 0.03$ & $102.12 \pm 1.43$ \\
\hline $\mathrm{F} 2$ & $498 \pm 5.49$ & $4.88 \pm 0.06$ & $4.6 \pm 0.67$ & $0.499 \pm 0.06$ & $98.36 \pm 0.78$ \\
\hline F3 & $497 \pm 4.24$ & $4.93 \pm 0.01$ & $4.7 \pm 0.46$ & $0.496 \pm 0.19$ & $99.27 \pm 0.47$ \\
\hline F4 & $502 \pm 0.92$ & $4.99 \pm 0.06$ & $4.8 \pm 0.81$ & $0.501 \pm 0.80$ & $102.69 \pm 0.36$ \\
\hline F5 & $498 \pm 2.19$ & $4.98 \pm 0.07$ & $4.8 \pm 0.49$ & $0.499 \pm 0.61$ & $96.76 \pm 0.91$ \\
\hline F6 & $503 \pm 0.93$ & $4.92 \pm 0.05$ & $4.7 \pm 0.12$ & $0.492 \pm 0.82$ & $98.81 \pm 0.46$ \\
\hline F7 & $504 \pm 0.23$ & $4.99 \pm 0.02$ & $4.8 \pm 0.62$ & $0.502 \pm 0.64$ & $99.19 \pm 0.66$ \\
\hline F8 & $498 \pm 0.98$ & $4.93 \pm 0.02$ & $5.0 \pm 0.71$ & $0.498 \pm 0.54$ & $100.98 \pm 1.09$ \\
\hline F9 & $502 \pm 0.12$ & $4.98 \pm 0.06$ & $4.9 \pm 0.63$ & $0.499 \pm 0.22$ & $98.99 \pm 0.09$ \\
\hline
\end{tabular}

${ }^{a}$ Each value represents mean $\pm S$. $D(n=20) ;{ }^{b}$ Each value represents mean $\pm S$. $D(n=10) ;{ }^{c}$ Each value represents mean $\pm S$. $D(n=6)$.

\section{In vitro drug release studies}

The cumulative percentage (\%) drug releases $(n=3)$ was shown in fig. 3. Based on measurement drug release profiles and other physical properties F1 was optimized. As a result F1, initiation containing both PEG 4000 and 6000, preferred proportion drug release and it follows zero order release kinetics. While the preparations comprising PEG 6000 revealed less release and perceived that the concentration of polymer rises the drug release was declined.

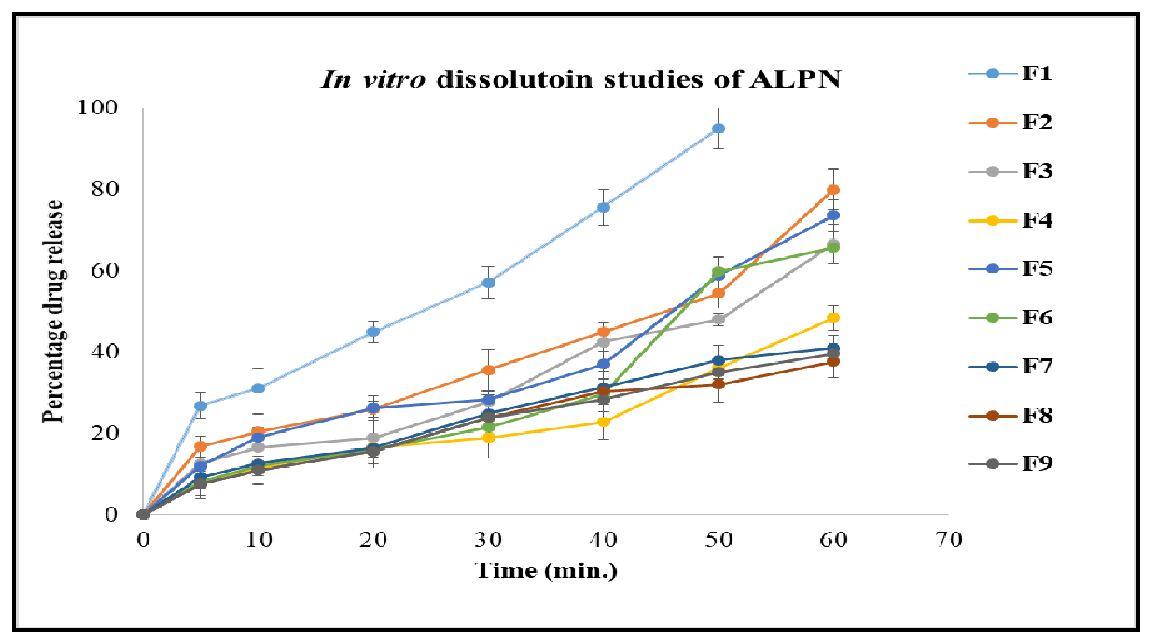

Fig. 3: In vitro dissolution data for formulations F1-F9; $(n=3)$

\section{CONCLUSION}

The dissolution rate can be extensively enhanced by formulating ALPN solid dispersion as a compressed tablet and with amplification, in the carrier content, there is a rise in the solubility also. It could be the best choice of treatment and accomplish good patient compliance. To conclude, it was revealed to be a successful methodology for illuminating the dissolution rate and thereby enhancing its systemic convenience.

\section{AUTHORS CONTRIBUTIONS}

All the author have contributed equally

\section{CONFLICT OF INTERESTS}

The authors declare that there is no conflict of interest

\section{REFERENCES}

1. Jaysweh JH, Dhaval AR, Kantilal RV. Orally disintegrating tablets: a review. Trop J Pharm Sci 2009;8:161-72.

2. Yadav VB, Yadav AV. Liquisolid granulation technique for tablet manufacturing: an overview. J Pharm Res 2009;2:670-4.

3. Clark's. Analysis of drugs and poisons in pharmaceutical body fluids and postmartum materials. $3^{\text {rd }}$ ed. London: Pharmaceutical Press; 2004. 
4. Benzra SA, Bennett TR. Analytical profiles of drug substances and excipients. Academic Press Inc 1978;7:1-18.

5. Day RO, Grham GG, Hicks M, Mclchlan AJ, Stocker SL, Williams KM. Clinical pharmacokinetics and pharmacodynamics of allopurinol. Clin Pharmacokinet 2007;46:623-44

6. Samy EM, Hassan MA, Tous SS, Rhodes CT. Improvement of availability of allopurinol from pharmaceutical dosage forms I: suppositories. Eur J Pharm Biopharm 2000;49:119-27.

7. Jagdale SC, Kuchekar BS, Chabukswar AR, Musale VP, Jadhao MA. Preparation and in vitro evaluation of allopurinol-gelucire 50/13 solid dispersions. Int J Adv Pharm Sci 2010;1:60-7.

8. Aggarwal S, Gupta GD, Chaudhary S. Solid dispersion as an eminent strategic approach in solubility enhancement of poorly soluble drugs. Int J Pharm Sci Res 2010;1:1-13.

9. Jadi RK, Tatikonda A, Veera Reedy PR, Venisetty R. Design and characterization of pregabalin swellable core osmotic pumps. Int J Pharm Res Allied Sci 2016;5:8-15.

10. Zedong D, Ashish C, Harpreet S, Duk SC, Hitesh C, Navnit S. Evaluation of solid state properties of solid dispersions prepared by hot-melt extrusion and solvent co-precipitation. Int J Pharm 2008;355:141-9.

11. Goldberg $\mathrm{AH}$, Galbaldi M, Kanig KL. Increasing dissolution rates and gastrointestinal absorption of drugs via solid solutions and eutectic mixtures III. Experimental evaluation of griseofulvinsuccinic acid solution. J Pharm Sci 1966;55:487-92.

12. Samy EM, Hassan MA, Tous SS, Rhodes CT. Improvement of availability of allopurinol from pharmaceutical dosage forms I: suppositories. Eur J Pharm Biopharm 2000;49:119-27.
13. Ahrabi SF, Madsen G, Dyrstad K, Sande SA, Graffner C. Development of pectin matrix tablets for colonic delivery of model drug ropivacaine. Eur J Pharm Sci 2000;10:43-52.

14. Sangeeta M, Abhisek P. Dissolution enhancement of seroquel by solid dispersion techniques. Asian J Pharm Clin Res 2016;9:284-7.

15. Niamprem P, Srinivas SP, Tiyaboonchai W. Development and characterization of indomethacin-loaded mucoadhesive nanostructured lipid carriers for topical ocular delivery. Int J Appl Pharm 2018;10:91-6.

16. Mura P, Furlanetto S, Cirri M, Maestrelli F, Marras AM, Pinzauti S. Optimization of glibenclamide tablet composition through the combined use of differential scanning calorimetry and doptimal mixture experimental design. J Pharm Biomed Anal 2005;37:65-71.

17. United States Pharmacopeial Convention. USP 31. United States Pharmacopeial Convention; 2007.

18. Costa P, Sousa Lobo JM. Modeling and comparison of dissolution profiles. Eur J Pharm Sci 2001;13:123-33.

19. Togaru V, Venisetty RK, Bakshi V, Jadi RK. Formulation development and in vitro evaluation of propranolol hydrochloride extended-release matrix tablets. Emerg L Sci Res 2017;3:38-47.

20. Geetha A, Rajendra Kumar J, Pavani U, Kalyani CH. Design and in vivo characterization of amlodipine besylate orodispersible tablets. J Global Trends Pharma Sci 2017;8:4325-36.

21. Jadi RK, Bomma R, Sellappan V. Development of a new single unit dosage form of propranolol $\mathrm{HCl}$ extended-release noneffervescent floating matrix tablets: In vitro and in vivo evaluation. J Appl Pharma Sci 2016;6:112-8. 